\title{
Quality of Isolated Pig Islets Is Improved Using Perfluorohexyloctane for Pancreas Storage in a Split Lobe Model
}

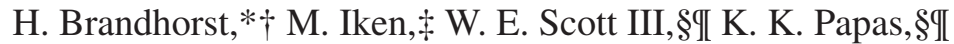 \\ B. Theisinger,\# P. R. Johnson, $\dagger$ O. Korsgren,* and D. Brandhorst* $\dagger$ \\ *Department of Immunology, Genetics and Pathology, Uppsala University, Uppsala, Sweden \\ $\dagger$ Nuffield Department of Surgical Sciences, University of Oxford, Oxford, UK \\ ¥Department of Gastroenterology, Hepatology and Endocrinology, University Hospital Hannover, Hannover, Germany \\ $\S$ Schulze Diabetes Institute for Immunology and Transplantation, Department of Surgery, \\ University of Minnesota, Minneapolis, MN, USA \\ IIInstitute for Cellular Transplantation, University of Arizona, Tuscon, AZ, USA \\ \#Novaliq GmbH, Heidelberg, Germany
}

\begin{abstract}
Pancreas transportation between donor center and islet production facility is frequently associated with prolonged ischemia impairing islet isolation and transplantation outcomes. It is foreseeable that shipment of pig pancreases from distant centralized biosecure breeding facilities to institutes that have a long-term experience in porcine islet isolation is essentially required in future clinical islet xenotransplantation. Previously, we demonstrated that perfluorohexyloctan (F6H8) is significantly more efficient to protect rat and human pancreata from ischemically induced damage compared to perfluorodecalin (PFD). To evaluate the effect of F6H8 on long-term stored pig pancreases in a prospective study, we utilized the split lobe model to minimize donor variability. Retrieved pancreases were dissected into the connecting and splenic lobe, intraductally flushed with UW solution and immersed alternately in either preoxygenated F6H8 or PFD for 8-10 h. Prior to pancreas digestion, the intrapancreatic $\mathrm{pO}_{2}$ and the ratio of ATP-to-inorganic phosphate was compared utilizing ${ }^{31} \mathrm{P}-\mathrm{NMR}$ spectroscopy. Isolated islets were cultured for $2-3$ days at $37^{\circ} \mathrm{C}$ and subjected to quality assessment. Pancreatic lobes stored in preoxygenated $\mathrm{F} 6 \mathrm{H} 8$ had a significantly higher intrapancreatic $\mathrm{pO}_{2}$ compared to pancreata in oxygen-precharged PFD $(10.11 \pm 3.87$ vs. $1.64 \pm 1.13 \mathrm{mmHg}, p<0.05)$. This correlated with a higher ATP-to-inorganic phosphate ratio $(0.30 \pm 0.04$ vs. $0.14 \pm 0.01)$. No effect was observed concerning yield and purity of freshly isolated islets. Nevertheless, a significantly improved glucose-stimulated insulin response, increased viability and postculture survival $(57.2 \pm 5.7$ vs. $39.3 \pm 6.4 \%, p<0.01)$ was measured in islets isolated from F6H8-preserved pancreata. The present data suggest that F6H8 does not increase islet yield but improves quality of pig islets isolated after prolonged cold ischemia.
\end{abstract}

Key words: Cold storage; Islet isolation; Organ preservation; Oxygenation; Pig pancreas

\section{INTRODUCTION}

Oxygen-precharged perfluorocarbons have been established in islet transplantation to reduce tissue damage induced by prolonged cold ischemia time (CIT) prior to isolation and subsequent transplantation $(15,22,35)$. One member of this chemical group, perfluorodecalin (PFD), has been extensively investigated in pancreases retrieved from porcine $(3,5)$ and human donors $(28,34)$. The promising results that were initially reported could not be confirmed in larger trials involving more than 350 human islet isolations $(9,21)$. Mathematical modeling on oxygen penetration depth demonstrated that, even at the most favorable conditions for completely saturated PFD, the oxygen penetration depth within a porcine or human average-sized pancreas at $8^{\circ} \mathrm{C}$ could be $1 \mathrm{~mm}$ at best, leaving the majority of the tissue anoxic $(1,25)$. Isolation experiments in porcine pancreases also raised questions about the efficiency of PFD $(4,18)$.

Comparative studies in rat and human pancreases suggested that pancreas preservation can be significantly improved replacing PFD by perfluorohexyloctane (F6H8), a semifluorinated alkane that is characterized

Received April 3, 2012; final acceptance July 25, 2012. Online prepub date: October 4, 2012.

Address correspondence to Daniel Brandhorst, Nuffield Department of Surgical Sciences, Oxford Center for Diabetes,

Endocrinology and Metabolism, University of Oxford, Churchill Drive, Oxford OX3 7LE, UK. Tel: +44-1865-8-57252; Fax: +44-1865-8-57299;

E-mail: Daniel.Brandhorst@nds.ox.ac.uk 
by an increased lipophilicity and lower density facilitating the penetration of oxygen into deeper tissue layers of stored organs (17). This modification significantly improved islet isolation outcome after prolonged CIT in terms of islet yield, viability, and functional integrity in comparison to PFD $(6,8)$.

In the present prospective study, we assessed the efficiency of F6H8 for long-term storage of pig pancreases procured for subsequent islet isolation utilizing the split lobe model in order to minimize donor-related variability (38). It is foreseeable that shipment of pig pancreases from distant centralized biosecure breeding facilities is essentially required in future clinical islet xenotransplantation (14).

Subjecting pig pancreas lobes to an estimated clinically relevant CIT of $8-10 \mathrm{~h}$, the present study demonstrates that pig pancreas oxygenation by means of preoxygenated F6H8 improves islet quality.

\section{MATERIALS AND METHODS}

All animal studies were approved by local ethics committees.

\section{Donor Animals and Pancreas Procurement}

Donor sows were housed for piglet production by the German Federal Research Institute for Animal Health (Neustadt, Germany) until loss of fertility and were slaughtered at the same institute. All retired breeders ( $\leq 24$ months) originated from the German Federal Hybrid Breeding Programme and were killed by exsanguination after carbon dioxide anesthesia. Ex situ dissection started after a primary warm ischemia time of $19 \pm 2 \mathrm{~min}$. Retrieved pancreases were trimmed and dissected into the splenic and connecting lobe and cannulated according to the recommendations of Ferrer et al. (11). These lobes were particularly used because of the difficulty to preserve the integrity of the duodenal lobe without substantially extending the warm ischemia time. After a secondary warm ischemia time of $21 \pm 1 \mathrm{~min}$, the pancreatic segments were intraductally flushed with cold University of Wisconsin solution (UWS, ViaSpan ${ }^{\oplus}$, DuPont Pharmaceuticals Ltd., Letchworth Garden City, Hertfordshire, UK) at a ratio of $1 \mathrm{ml} / \mathrm{g}$ trimmed tissue. Total warm ischemia time accumulated to $40 \pm 1 \mathrm{~min}$.

\section{Pancreas Cold Storage}

UWS-flushed pancreases were oxygenated utilizing the one-layer method as previously described (3). Briefly, the splenic and connecting lobes were immersed in $600 \mathrm{ml}$ of either PFD or F6H8 (Novaliq GmbH, Heidelberg, Germany) in an alternate manner to consider the asymmetric morphology of the porcine pancreas $(23,36)$. Both oxygen carriers had been precharged for 15 min with $100 \%$ oxygen at a flow rate of 2,000 $\mathrm{ml} / \mathrm{min}$. Subsequently, the segments were shipped on ice to the isolation facility.

During preservation, the ratio of adenosine-triphosphate (ATP) to inorganic phosphate was assessed in the stored tissue by a noninvasive method utilizing ${ }^{31} \mathrm{P}$-nuclear magnetic resonance spectroscopy (NMR) in a small series of experiments $(n=3)$, to measure ${ }^{31} \mathrm{P}$, a naturally abundant isotope, as previously described (30). Briefly, immediately after retrieval, pancreas lobes were intraductally injected with $1.0 \mathrm{ml} / \mathrm{g}$ histidine-tryptophan-ketoglutarate (HTK, Essential Pharmaceuticals, Newtown, PA, USA) solution instead of UWS to minimize background noise induced by phosphate dissolved in UWS. Afterwards, pancreatic segments were alternately incubated in either oxygenprecharged PFD or F6H8 and placed in a surface coil positioned in a 1.5-T magnet with a warm bore diameter of $680 \mathrm{~mm}$ and a gradient of $550 \mathrm{~mm}$ (Magnex Scientific, Abingdon, UK). The areas of the $\alpha-, \beta-$, and $\gamma$-ATP peaks were visualized by means of a Tecmag Apollo spectrometer (Tecmag Inc., Houston, TX, USA) and were compared with the area of the inorganic phosphate peak to monitor the bioenergetic status of the organs.

Immediately after arrival in the laboratory, the intrapancreatic partial oxygen pressure $\left(\mathrm{pO}_{2}\right)$ was measured in both segments at a depth of 5-7 mm utilizing an optic fiber sensor housed in a cannula (Precision Sensing $\mathrm{GmbH}$, Regensburg, Germany) that was introduced in the tissue as previously described (6). This procedure resulted in leakage during collagenase infusion and so the number of experiments was limited to six. Total CIT was defined as the interval between intraductal infusion of UWS and injection of the collagenase blend into the pancreatic duct.

\section{Islet Isolation}

After $\mathrm{pO}_{2}$ measurement pancreas lobes were intraductally distended with collagenase NB-1 supplemented with neutral protease NB (Serva Electrophoresis, Uetersen, Germany). To provide similar conditions for each of the lobes, collagenase and neutral protease were adjusted to a concentration of 15 PZ-U and 1.3 DMC-U/g trimmed tissue weight and dissolved in $1 \mathrm{ml} / \mathrm{g}$ cold UWS, respectively. Isolation and purification was performed as previously described with minimal modifications regarding the digestion temperature kept in a range from $28^{\circ} \mathrm{C}$ to $32^{\circ} \mathrm{C}$ during recirculation and dilution phase (7). Purified islet fractions were washed twice in Hank's balanced salt solution supplemented with $10 \%$ newborn calf serum and collected finally in $100 \mathrm{ml}$ of bicarbonate-free CMRL 1066 supplemented with $25 \mathrm{mM}$ HEPES, $1 \mathrm{mM}$ pyruvate, $10 \mathrm{mM}$ nicotinamide (all PAA, Pasching, Austria), 20\% porcine serum, $2.5 \mathrm{mM}$ L-glutamine, $100 \mathrm{U} / \mu \mathrm{g} / \mathrm{ml}$ penicillin-streptomycin (all Gibco, Life Technologies, Paisley, Scotland, UK), and 
$20 \mu \mathrm{g} / \mathrm{ml}$ ciprofloxacin (Bayer, Leverkusen, Germany). Islet culture was performed in gas-permeable culture bags (Baxter Healthcare, Newbury, UK) incubated in humidified normal air for $2-3$ days at $37^{\circ} \mathrm{C}$.

\section{Islet Characterization}

Subsequent to purification and after culture islet yield and purity were determined in a standardized procedure converting islet yield to islet equivalents (IEQ) with an average diameter of $150 \mu \mathrm{m}$ (26). Islet ATP content was measured in aliquots of freshly isolated islets utilizing the ATP Lite assay kit (Perkin Elmer, Seer Green, UK). ATP was normalized to islet DNA content determined by means of a fluorometric assay (Picogreen; Life Technologies, Paisley, Scotland, UK). Determination of fluorometric membrane integrity was performed utilizing $25 \mu \mathrm{mol} / \mathrm{L}$ of Syto- 13 and $50 \mu \mathrm{mol} / \mathrm{L}$ of Sytox Orange (Molecular Probes, Life Technologies, Paisley, Scotland, UK) for staining of viable and dead cells, respectively (6). Islet in vitro function was assessed during static glucose (Sigma-Aldrich, AB., Stockholm, Sweden) incubation of islets precultured for 23 days at $37^{\circ} \mathrm{C}$. Twenty hand-selected islets with an average diameter of 150-200 $\mu \mathrm{m}$ were sequentially incubated in duplicate first for $45 \mathrm{~min}$ in bicarbonate-free CMRL 1066 supplemented with $2 \mathrm{mmol} / \mathrm{L}$ glucose followed by $45 \mathrm{~min}$ of incubation at $20 \mathrm{mmol} / \mathrm{L}$ glucose followed finally by a second 45 -min period at $2 \mathrm{mmol} / \mathrm{L}$ glucose. The glucose stimulation index was calculated by dividing the insulin release at $20 \mathrm{mmol} / \mathrm{L}$ glucose by the mean of the basal periods. After incubation islets were recovered and sonified in acid ethanol for subsequent determination of intracellular insulin content (6). Intracellular and released insulin was measured utilizing an enzyme immunoassay specific for pig insulin (Mercodia, Uppsala, Sweden) and normalized to islet DNA content.

Islet in vivo function was assessed in NMRI nude mice (Scanbur, Sollentuna, Sweden) rendered diabetic by a single intravenous injection of $90 \mu \mathrm{g} / \mathrm{g}$ alloxan (SigmaAldrich) 3 days prior to transplantation of an aliquot of 1,750 IEQ beneath the kidney capsule. Blood samples were taken from the recipients' tail vein and analyzed utilizing a one-touch glucosemeter (Bayer, Leverkusen, Germany). Pretransplant, the nonfasting serum glucose levels of all recipients exceeded $400 \mathrm{mg} / \mathrm{dl}$. After transplantation, nonfasting serum glucose levels $<200 \mathrm{mg} / \mathrm{dl}$ were defined as normoglycemic and considered as graft function. Thirty days posttransplant nephrectomy of graftbearing kidneys was performed to demonstrate immediate return of hyperglycemia.

\section{Data Analysis}

All statistical analysis was performed utilizing Prism 5.0d for MacIntosh (GraphPad, La Jolla, CA, USA). Comparisons of data were carried out by Wilcoxon test and Fisher's exact test. Repeated measurements were analyzed using the Friedman test prior to multiple comparisons using Dunn's test. Differences are considered significant at $p<0.05$. Values of $p>0.05$ are termed nonsignificant (NS). For clarity, results are expressed as mean \pm standard error (SEM) rather the the correct nonparametric measures of median and quartiles.

\section{RESULTS}

\section{Pancreas Storage Variables}

Measurement of intrapancreatic $\mathrm{pO}_{2}(n=6)$ revealed that storage of pancreatic segments in preoxygenated $\mathrm{F} 6 \mathrm{H} 8$ resulted in a significantly higher $\mathrm{pO}_{2}(10.11 \pm 3.87 \mathrm{mmHg})$ compared to lobes preserved in oxygen-charged PFD $(1.64 \pm 1.13, n=6, p<0.05)$. This observation corresponded with a higher ATP-to-inorganic phosphate ratio in F6H8-stored lobes $(0.30 \pm 0.04$ vs. $0.14 \pm 0.01)$ as measured by ${ }^{31} \mathrm{P}-\mathrm{NMR}$ during $8 \mathrm{~h}$ of cold storage in a small series of experiments $(n=3)$. In agreement, the ATP content in freshly isolated pig islets recovered from pancreatic lobes that were preserved in preoxygenated F6H8 was significantly increased compared to lobes stored in precharged PFD [ $290 \pm 60$ vs. $203 \pm 31$ ATP (pg/ng DNA), $p<0.01]$. No significant difference was found between PFD $(413 \pm 23 \mathrm{mmHg})$ and F6H8 $(392 \pm 43 \mathrm{mmHg}, \mathrm{NS})$ with respect to media $\mathrm{pO}_{2}$ after having been used for storage of porcine pancreatic segments for $9.8 \pm 1.5$ and $9.6 \pm 1.5 \mathrm{~h}$ of cold ischemia, respectively.

\section{Islet Isolation Outcome}

Isolation variables such as digestion time, percentage of undigested tissue, and packed volume of digested tissue did not vary significantly after utilization of $\mathrm{F} 6 \mathrm{H} 8$ or PFD (Table 1). No significant differences were observed between F6H8 and PFD with respect to total islet yield $(260,300 \pm 30,180$ vs. $232,500 \pm 42,930$ IEQ $)$ and corresponding insulin content $(911 \pm 212$ vs. $953 \pm 204 \mu \mathrm{g} / \mathrm{lobe})$

Table 1. Islet Isolation Variables

\begin{tabular}{|c|c|c|c|c|c|c|c|c|}
\hline \multirow{2}{*}{$\begin{array}{l}\text { Oxygen } \\
\text { Carrier }\end{array}$} & \multirow[b]{2}{*}{$n$} & \multirow{2}{*}{$\begin{array}{l}\text { Digestion } \\
\text { Time (min) }\end{array}$} & \multirow{2}{*}{$\begin{array}{l}\text { Undigested } \\
\text { Tissue }(\%)\end{array}$} & \multirow{2}{*}{$\begin{array}{c}\text { Packed } \\
\text { Tissue }(\mathrm{ml} / \mathrm{g})\end{array}$} & \multicolumn{2}{|c|}{ Yield } & \multirow[b]{2}{*}{ Purity (\%) } & \multirow{2}{*}{$\begin{array}{c}\text { Insulin Content } \\
(\mu \mathrm{g} / \text { Lobe })\end{array}$} \\
\hline & & & & & IEQ/Lobe & $\mathrm{IEQ} / \mathrm{g}$ & & \\
\hline $\mathrm{H} 8$ & 10 & $24.5=$ & $12.7 \pm 2.2$ & $0.35 \pm 0.04$ & $0,300 \pm 30,180$ & $3020+32$ & $85.0 \pm 4.3$ & 911 \\
\hline PFD & 10 & $24.3 \pm 1.4$ & $10.9 \pm 1.8$ & $0.33 \pm 0.04$ & $232,500 \pm 42,930$ & $2,940 \pm 720$ & $83.3 \pm 5.3$ & $953 \pm 204$ \\
\hline
\end{tabular}

F6H8, perfluorohexyloctane; PFD, perfluorodecalin; IEQ, islet equivalent. 
Table 2. Porcine Islet Quality Assessment

\begin{tabular}{|c|c|c|c|c|c|c|}
\hline $\begin{array}{l}\text { Oxygen } \\
\text { Carrier }\end{array}$ & $n$ & $\begin{array}{c}\text { Postculture } \\
\text { Survival (\%) }\end{array}$ & $\begin{array}{l}\text { Stimulation } \\
\text { Index }\end{array}$ & $\begin{array}{c}\text { Insulin Content } \\
\text { (ng/ng DNA) }\end{array}$ & Viability (\%) & $\begin{array}{c}\text { ATP } \\
\text { (pg/ng DNA) }\end{array}$ \\
\hline F6H8 & 9 & $57.4 \pm 5.7$ & $2.28 \pm 0.35$ & $6.0 \pm 2.2$ & $81.8 \pm 2.6$ & $290 \pm 60$ \\
\hline $\begin{array}{l}\text { PFD } \\
p \text { value }\end{array}$ & 9 & $\begin{array}{c}39.3 \pm 6.4 \\
<0.01\end{array}$ & $\begin{array}{c}1.90 \pm 0.42 \\
<0.05\end{array}$ & $\begin{array}{l}5.5 \pm 2.1 \\
>0.05\end{array}$ & $\begin{array}{c}75.9 \pm 2.6 \\
<0.05\end{array}$ & $\begin{array}{c}203 \pm 31 \\
<0.01\end{array}$ \\
\hline
\end{tabular}

F6H8, perfluorohexyloctane; PFD, perfluorodecalin.

(Table 1). Likewise, islet yield per gram trimmed pancreatic tissue $(3,020 \pm 330$ vs. $2,940 \pm 270 \mathrm{IEQ} / \mathrm{g})$ and final islet purity $(85.0 \pm 4.3$ vs. $83.3 \pm 5.3 \%$ ) (Table 1 ) did not differ as well.

However, islet quality assessment revealed that significantly more pig islets survived during culture at $37^{\circ} \mathrm{C}$ when isolated from pancreases stored in preoxygenated $\mathrm{F} 6 \mathrm{H} 8$ $(57.2 \pm 5.7 \%$ vs. $39.3 \pm 6.4 \%, p<0.01)$ as shown in Table 2 . Higher survival of cultured islets isolated from F6H8preserved organs was associated with increased islet viability $(81.8 \pm 2.6 \%$ vs. $75.9 \pm 2.6 \%, p<0.05)$. Pancreas oxygenation influenced also in vitro function determined as glucose stimulation index during static incubation $(2.28 \pm 0.35$ vs. $1.90 \pm 0.42, p<0.05$ ). Moreover, islets isolated from PFDstored pancreases were not capable of downregulating insulin release after switching from 20 to $2 \mathrm{mmol} / \mathrm{L}$ glucose concentration as demonstrated in Figure 1. Intracellular insulin content was not altered by the preservation method used during cold storage (Table 2).

Posttransplant function of pig islets cultured for 3 days was assessed after transplantation beneath the kidney capsule of diabetic nude mice. A gradual decrease in hyperglycemia was observed until alloxan-injected recipients became normoglycemic through transplanted pig islets (Fig. 2). Altogether, 9 of $10(90.0 \%)$ and 7 of $8(87.5 \%)$ diabetic recipients were cured by islets from F6H8- or PFD-oxygenated pig pancreases (NS by Fisher's exact test), respectively.

\section{DISCUSSION}

Several studies previously demonstrated that storage of ischemic pig pancreases in oxygenated PFD improves islet isolation outcome in comparison to cold storage in UWS $(5,12)$. The present study was initiated to investigate whether PFD can be successfully replaced in a large animal model utilizing an oxygen carrier with different chemical characteristics. In order to provide similar conditions for both experimental groups, the pancreas split lobe model was utilized (38). Because of the asymmetric morphology of the porcine pancreas, it was not possible to provide perfectly identical conditions for the paired experiments particularly concerning the potential native islet yield within the connecting and splenic lobe. With respect to this parameter, previous histological observations are not consistent and seem to depend on the pig breed used $(23,36)$. Regardless of these concerns, we did not expect any bias for the present study, since the different lobes were symmetrically allocated (five splenic and five connecting lobes) for both PFD- and F6H8-preserved organs and were digested with the same concentration of enzymes adjusted according to trimmed tissue weight.

The present report shows that pig islet quality can be even more enhanced after $8-10 \mathrm{~h}$ of cold storage when PFD is replaced by the new oxygen carrier F6H8. These findings confirm previous experiments in rat and human pancreases, suggesting that $\mathrm{F} 6 \mathrm{H} 8$ improves pancreas preservation during 24-h storage prior to islet isolation $(6,8)$. The specific structure of $\mathrm{F} 6 \mathrm{H} 8$, belonging to the group of semifluorinated alkanes, results in a lower density and 20 -fold higher lipophilicity compared to PFD $(17,24)$. These characteristics seem to favor the penetration of the oxygen carrier into deeper tissue layers resulting in a still limited but nevertheless enhanced oxygenation of the stored tissue as demonstrated by intrapancreatic $\mathrm{pO}_{2}$ determination and

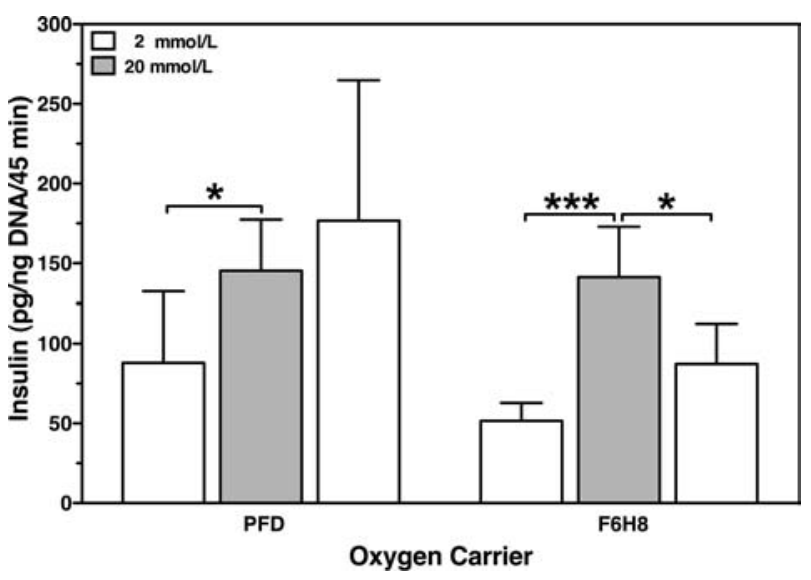

Figure 1. Glucose-stimulated insulin release. Isolated pig islets precultured for 2 days at $37^{\circ} \mathrm{C}$ were sequentially incubated for $45 \mathrm{~min}$ in 2 (white bars), 20 (gray bars), and again $2 \mathrm{mmol} / \mathrm{L}$ of glucose $(n=9)$. Insulin release was normalized to islet DNA content. Wilcoxon test revealed $* p<0.05$ and $* * * p<0.001$ as indicated. F6H8, perfluorohexyloctane; PFD, perfluorodecalin. 


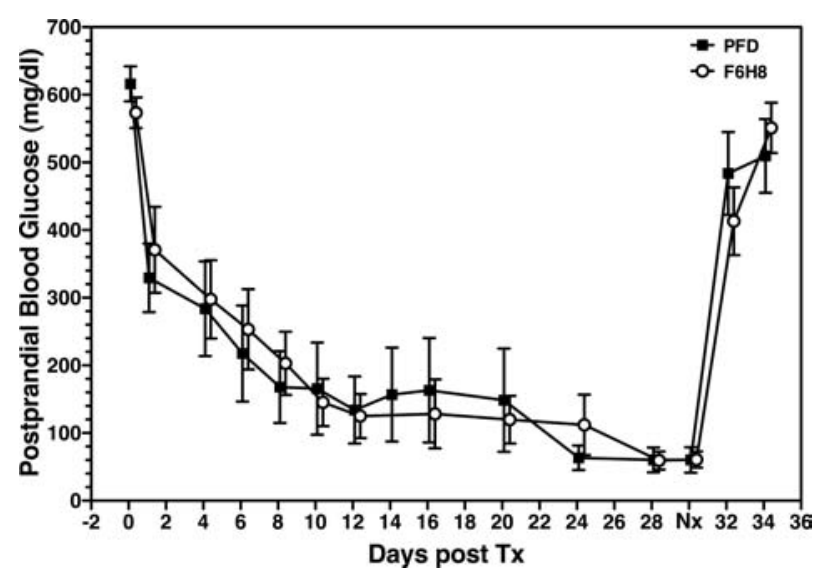

Figure 2. Posttransplant function of adult pig islets isolated from pancreatic lobes stored for $8-10 \mathrm{~h}$ in preoxygenated PFD (black squares, $n=8$ ) or F6H8 (open circles, $n=10$ ). Aliquots of 1,750 islet equivalents were transplanted beneath the kidney capsule of alloxan-treated diabetic NMRI nude mice after 3 days of culture at $37^{\circ} \mathrm{C}$. Nephrectomy (Nx) of graft-bearing kidneys was performed on day 30 as indicated. Data are calculated from four individual islet preparations.

increased pancreatic and islet ATP content during cold storage. Maintenance of ATP synthesis during cold ischemia appears to be important to preserve the structural integrity of the acinar tissue (20) and to prevent premature intracellular protease activation and subsequent exocrine tissue dissociation during prolonged cold ischemia $(19,37)$. This is particularly relevant for the porcine pancreas, which is more susceptible toward ischemic damage than other large animal models (16) and which can easily be dissociated at low temperatures without adding collagenase and neutral protease (29). It is likely, that extensive autolysis of acinar structures affects the functional and morphological integrity of adjacent islets as well $(13,32)$.

The importance of an increased ATP content for islet morphological and functional integrity is reflected by a substantially higher survival after $37^{\circ} \mathrm{C}$ culture. Islets, isolated from F6H8-preserved pancreases, were also characterized by an increased viability and improved glucosestimulated insulin secretion. The enhanced functional capacity after pancreas oxygenation was demonstrated by an intact downregulation of insulin release after switching from high to low glucose concentrations while this physiological response was missing when pancreases were stored in preoxygenated PFD.

Islets that were recovered after culture functioned equally in diabetic nude mice regardless whether the pancreases were stored in PFD or F6H8. This may be explained by selection of intact islets during culture at $37^{\circ} \mathrm{C}(2)$, which seems to be particularly relevant for pig islets known to fragment easily during culture (33). It was shown that culture at $37^{\circ} \mathrm{C}$ removes all predamaged islets thereby leveling potential differences with regard to morphological integrity and improving functional capacity $(10,27)$. A critical point of the present study is therefore that the diabetic nude mice were not treated with a marginal islet mass.

In summary, the present study demonstrates that the quality of pig islets isolated after long-term storage is significantly improved when pancreases are oxygenated utilizing oxygen-precharged F6H8 in comparison to PFD. This new oxygen carrier has lipophilic characteristics and improves the oxygenation of deeper pancreatic tissue layers, thereby increasing the ATP synthesis in islets, which seems to be important for enhanced islet survival after culture. As previously shown, techniques are existing that have a high efficiency to optimize intrapancreatic oxygenation (31). Nevertheless, these advanced techniques are still at the investigational stage, whereas our approach could be immediately translated to the clinic and is essentially as simple as the static cold storage methods currently used.

ACKNOWLEDGMENTS: We gratefully thank Karin Andersson for her assistance in the laboratory. This work was supported in part by the Juvenile Diabetes Research Foundation International (Grant 1-2007-198) and by a grant of the German Ministry for Economy and Technology (BMWi). Olle Korsgren is in part supported by the National Institutes of Health (2U01AI065192-06). Bastian Theisinger is employed by Novaliq GmbH as indicated. Practical work related to isolation and quality assessent of islets was performed at the Department of Immunology, Genetics and Pathology, Uppsala University, Sweden. Pancreatic ATP content by means of ${ }^{31} P$-NMR was assessed at the Schulze Diabetes Institute for Immunology and Transplantation, University of Minnesota, Minneapolis, USA. Data analysis and writing of the manuscript were done at the Nuffield Department of Surgical Sciences at the Oxford University, UK. Klearchos Papas and William E. Scott III are currently employed at the Institute for Cellular Transplantation, University of Arizona, Tuscon, USA.

\section{REFERENCES}

1. Avgoustiniatos, E. S.; Hering, B. J.; Papas, K. K. The rat pancreas is not an appropriate model for testing the preservation of the human pancreas with the two-layer method. Transplantation 81(10):1471-1472; author reply 1472; 2006.

2. Brandhorst, D.; Brandhorst, H.; Hering, B. J.; Bretzel, R. G. Long-term survival, morphology and in vitro function of isolated pig islets under different culture conditions. Transplantation 67(12):1533-1541; 1999.

3. Brandhorst, D.; Iken, M.; Brendel, M. D.; Bretzel, R. G.; Brandhorst, H. Successful pancreas preservation by a perfluorocarbon-based one-layer method for subsequent pig islet isolation. Transplantation 79(4):433-437; 2005.

4. Brandhorst, D.; Iken, M.; Bretzel, R. G.; Brandhorst, H. Pancreas storage in oxygenated perfluorodecalin does not restore posttransplant function of isolated pig islets predamaged by warm ischemia. Xenotransplantation 13(5):465-470; 2006.

5. Brandhorst, D.; Iken, M.; Tanioka, Y.; Brendel, M. D.; Bretzel, R. G.; Brandhorst, H. Influence of collagenase 
loading on long-term preservation of pig pancreas by the two-layer method for subsequent islet isolation. Transplantation 79(1):38-43; 2005.

6. Brandhorst, H.; Asif, S.; Andersson, K.; Theisinger, B.; Andersson, H. H.; Felldin, M.; Foss, A.; Salmela, K.; Tibell, A.; Tufveson, G.; Korsgren, O.; Brandhorst, D. A new oxygen carrier for improved long-term storage of human pancreata before islet isolation. Transplantation 89(2):155-160; 2010.

7. Brandhorst, H.; Brandhorst, D.; Hering, B. J.; Bretzel, R. G. Significant progress in porcine islet mass isolation utilizing liberase HI for enzymatic low-temperature pancreas digestion. Transplantation 68(3):355-361; 1999.

8. Brandhorst, H.; Theisinger, B.; Yamaya, H.; Henriksnas, J.; Carlsson, P. O.; Korsgren, O.; Brandhorst, D. Perfluorohexyloctane improves long-term storage of rat pancreata for subsequent islet isolation. Transpl. Int. 22(10):1017-1022; 2009.

9. Caballero-Corbalan, J.; Eich, T.; Lundgren, T.; Foss, A.; Felldin, M.; Kallen, R.; Salmela, K.; Tibell, A.; Tufveson, G.; Korsgren, O.; Brandhorst, D. No beneficial effect of twolayer storage compared with UW-storage on human islet isolation and transplantation. Transplantation 84(7):864-869; 2007.

10. Davalli, A. M.; Bertuzzi, F.; Socci, C.; Scaglia, L.; Gavazzi, F.; Freschi, M.; DiCarlo, V.; Pontiroli, A. E.; Pozza, G. Paradoxical release of insulin by adult pig islets in vitro. Recovery after culture in a defined tissue culture medium. Transplantation 56(1):148-154; 1993.

11. Ferrer, J.; Scott, 3rd., W. E.; Weegman, B. P.; Suszynski, T. M.; Sutherland, D. E.; Hering, B. J.; Papas, K. K. Pig pancreas anatomy: Implications for pancreas procurement, preservation, and islet isolation. Transplantation 86(11):1503-1510; 2008.

12. Gioviale, M. C.; Damiano, G.; Palumbo, V. D.; Bellavia, M.; Cacciabaudo, F.; Cassata, G.; Puleio, R.; Altomare, R.; Lo Monte, A. I. Pancreatic islets from non-heart-beating donor pig: Two-layer preservation method in an in vitro porcine model. Int. J. Artif. Organs 34(6):519-525; 2011.

13. Heiser, A.; Ulrichs, K.; Muller-Ruchholtz, W. Prophylactic trypsin inhibition during the isolation procedure guarantees reproducible, high porcine islet yields. Xenotransplantation $1: 66-68 ; 1994$.

14. Hering, B. J.; Cooper, D. K.; Cozzi, E.; Schuurman, H. J.; Korbutt, G. S.; Denner, J.; O’Connell, P. J.; Vanderpool, H. Y.; Pierson, 3rd., R. N. The International Xenotransplantation Association consensus statement on conditions for undertaking clinical trials of porcine islet products in Type 1 diabetesexecutive summary. Xenotransplantation 16(4):196-202; 2009.

15. Hering, B. J.; Kandaswamy, R.; Harmon, J. V.; Ansite, J. D.; Clemmings, S. M.; Sakai, T.; Paraskevas, S.; Eckman, P. M.; Sageshima, J.; Nakano, M.; Sawada, T.; Matsumoto, I.; Zhang, H. J.; Sutherland, D. E.; Bluestone, J. A. Transplantation of cultured islets from two-layer preserved pancreases in Type 1 diabetes with anti-CD3 antibody. Am. J. Transplant. 4(3):390-401; 2004.

16. Hesse, U. J.; Troisi, R.; Jacobs, B.; Berrevoet, F.; De Laere, S.; Maene, L.; Vanden Broucke, C.; de Hemptinne, B. Cold preservation of the porcine pancreas with histidinetryptophan-ketoglutarate solution. Transplantation 66(9): 1137-1141; 1998.
17. Hoerauf, H.; Kobuch, K.; Dresp, J.; Menz, D. H. Combined use of partially fluorinated alkanes, perfluorocarbon liquids and silicone oil: An experimental study. Graefes Arch. Clin. Exp. Ophthalmol. 239(5):373-381; 2001.

18. Iken, M.; Brandhorst, H.; Korsgren, O.; Brandhorst, D. Pig pancreas oxygenation at $20^{\circ} \mathrm{C}$ increases islet ATP generation but deteriorates islet function. Cell Transplant. 18(7):745-751; 2009.

19. Jonsson, P.; Kallen, R.; Montgomery, A.; Borgstrom, A. Protease activation in the porcine pancreatic allograft during preservation. Pancreas 11(3):256-260; 1995.

20. Kawamura, T.; Kuroda, Y.; Suzuki, Y.; Fujiwara, H.; Fujino, Y.; Yamamoto, K.; Saitoh, Y. Seventy-two-hour preservation of the canine pancreas by the two-layer (Euro-Collins' solution/ perfluorochemical) cold storage method. Transplantation 47(5):776-778; 1989.

21. Kin, T.; Mirbolooki, M.; Salehi, P.; Tsukada, M.; O’Gorman, D.; Imes, S.; Ryan, E. A.; Shapiro, A. M.; Lakey, J. R. Islet isolation and transplantation outcomes of pancreas preserved with University of Wisconsin solution versus two-layer method using preoxygenated perfluorocarbon. Transplantation 82(10): 1286-1290; 2006.

22. Lee, T. C.; Barshes, N. R.; Brunicardi, F. C.; Alejandro, R.; Ricordi, C.; Nguyen, L.; Goss, J. A. Procurement of the human pancreas for pancreatic islet transplantation. Transplantation 78(3):481-483; 2004.

23. Marchetti, P.; Giannarelli, R.; di Carlo, A.; Vassalle, A.; Picaro, L.; Gattai, V.; Pozzolini, L.; Masoni, A.; Navalesi, R. Morphometrical and immunocytochemical characterization of the porcine endocrine pancreas. Transplant. Proc. 22(2):727-728; 1990.

24. Meinert, H.; Roy, T. Semifluorinated alkanes-a new class of compounds with outstanding properties for use in ophthalmology. Eur. J. Ophthalmol. 10(3):189-197; 2000.

25. Papas, K. K.; Hering, B. J.; Gunther, L.; Rappel, M. J.; Colton, C. K.; Avgoustiniatos, E. S. Pancreas oxygenation is limited during preservation with the two-layer method. Transplant. Proc. 37(8):3501-3504; 2005.

26. Ricordi, C.; Gray, D. W.; Hering, B. J.; Kaufman, D. B.; Warnock, G. L.; Kneteman, N. M.; Lake, S. P.; London, N. J.; Socci, C.; Alejandro, R.; Zeng, Y.; Scharp, D. W.; Viviani, G.; Falqui, L.; Tzakis, A.; Bretzel, R. G.; Federlin, K.; Pozza, G.; James, R. F. L.; Rajotte, R. V.; Di Carlo, V.; Morris, P. J.; Sutherland, D. E.; Starzl, T. E.; Mintz, D. H.; Lacy, P. E. Islet isolation assessment in man and large animals. Acta Diabetol. Lat. 27(3):185-195; 1990.

27. Rijkelijkhuizen, J. K.; van der Burg, M. P.; Tons, A.; Terpstra, O. T.; Bouwman, E. Pretransplant culture selects for highquality porcine islets. Pancreas 32(4):403-407; 2006.

28. Salehi, P.; Mirbolooki, M.; Kin, T.; Tsujimura, T.; Shapiro, A. M.; Churchill, T. A.; Lakey, J. R. Ameliorating injury during preservation and isolation of human islets using the two-layer method with perfluorocarbon and UW solution. Cell Transplant. 15(2):187-194; 2006.

29. Sato, S.; Ohgawara, H.; Katagiri, N.; Nakagawa, Y.; Aikawa, E.; Omori, Y.; Ota, K. A simple method for purification of adult pig pancreatic endocrine cells. Pancreas 14(4):400406; 1997.

30. Scott, 3rd., W. E.; Matsumoto, S.; Tanaka, T.; Avgoustiniatos, E. S.; Graham, M. L.; Williams, P. C.; Tempelman, L. A.; Sutherland, D. E.; Hering, B. J.; Hammer, B. E.; Papas, K. K. Real-time noninvasive assessment of pancreatic ATP levels 
during cold preservation. Transplant. Proc. 40(2):403-406; 2008.

31. Scott, 3rd., W. E.; Weegman, B. P.; Ferrer-Fabrega, J.; Stein, S. A.; Anazawa, T.; Kirchner, V. A.; Rizzari, M. D.; Stone, J.; Matsumoto, S.; Hammer, B. E.; Balamurugan, A. N.; Kidder, L. S.; Suszynski, T. M.; Avgoustiniatos, E. S.; Stone, S. G.; Tempelman, L. A.; Sutherland, D. E.; Hering, B. J.; Papas, K. K. Pancreas oxygen persufflation increases ATP levels as shown by nuclear magnetic resonance. Transplant. Proc. 42(6):2011-2015; 2010.

32. Tanioka, Y.; Hering, B. J.; Sutherland, D. E.; Kronson, J. W.; Kuroda, Y.; Gilmore, T. R.; Aasheim, T. C.; Rusten, M. C.; Leone, J. P. Effect of pancreatic warm ischemia on islet yield and viability in dogs. Transplantation 64(12):1637$1641 ; 1997$.

33. Toso, C.; Brandhorst, D.; Oberholzer, J.; Triponez, F.; Buhler, L.; Morel, P. Isolation of adult porcine islets of Langerhans. Cell Transplant. 9(3):297-305; 2000.

34. Tsujimura, T.; Kuroda, Y.; Churchill, T. A.; Avila, J. G.; Kin, T.; Shapiro, A. M.; Lakey, J. R. Short-term storage of the ischemically damaged human pancreas by the two-layer method prior to islet isolation. Cell Transplant. 13(1):67-73; 2004.

35. Tsujimura, T.; Kuroda, Y.; Kin, T.; Avila, J. G.; Rajotte, R. V.; Korbutt, G. S.; Ryan, E. A.; Shapiro, A. M.; Lakey, J. R. Human islet transplantation from pancreases with prolonged cold ischemia using additional preservation by the two-layer (UW solution/perfluorochemical) cold-storage method. Transplantation 74(12):1687-1691; 2002.

36. Ulrichs, K.; Bosse, M.; Heiser, A.; Eckstein, V.; Wacker, H. H.; Thiede, A.; Muller-Ruchholtz, W. Histomorphological characteristics of the porcine pancreas as a basis for the isolation of islets of Langerhans. Xenotransplantation 2:176$187 ; 1995$.

37. Wahlberg, J.; Southard, J. H.; Belzer, F. O. Preservationinduced pancreatitis in an isolated perfused pancreas model in the dog. Transpl. Int. 2(3):165-167; 1989.

38. Weegman, B. P.; Taylor, M. J.; Baicu, S.; Scott, 3rd., W. E.; Mueller, K. R.; Kitzmann, J. D.; Rizzari, M. D.; Papas, K. K. Hypothermic perfusion preservation of pancreas for islet grafts: Validation using a split lobe porcine model. Cell Med. 2(3):105-110; 2012. 
